\title{
The Relative Power of Employment-to-Employment Reallocation and Unemployment Exits in Predicting Wage Growth ${ }^{\text {円 }}$
}

\author{
By Giuseppe Moscarini and Fabien Postel-VinaY*
}

In previous work (Moscarini and Postel-Vinay 2016), we investigated the hypothesis that labor demand is transmitted to wage growth primarily through Employer-to-Employer (EE) transitions. Workers often quit their jobs when they receive better offers. Therefore, the more frequent EE transitions, the higher the pace of reallocation toward high wage jobs, and the higher average wage growth. Also, the more opportunities workers have to quit, the more aggressive are their employers' wage responses to try and retain them. We derived these predictions from the comparative statics response of steady-state equilibrium to aggregate profitability shocks in the canonical Burdett and Mortensen (1998) wage posting model. Firms offer contracts and commit to deliver the resulting payments to workers, but do not renegotiate when their employees receive outside offers. As a result, job stayers never receive wage raises, unless the economy is hit by aggregate shocks which lead firms to adjust their optimal wage offers, as we showed in Moscarini and Postel-Vinay (2013). In contrast, the canonical search and matching model of Mortensen and Pissarides (1994) postulates that wages are the result of pairwise bargaining, unemployment being the worker's disagreement option. In that model, it is the exit rate from unemployment to employment (UE) that best approximates the worker's ability to extract rents from his employer. We then showed using longitudinal micro data from the Survey

\footnotetext{
* Moscarini: Department of Economics, Yale University, PO Box 208268, New Haven, CT 06520 and NBER (e-mail: giuseppe.moscarini@yale.edu); Postel-Vinay: Department of Economics, University College London, Drayton House, 30 Gordon Street, London WC1H 0AX, UK, and IFS (e-mail: f.postel-vinay@ucl.ac.uk). We thank our discussant John Haltiwanger for comments. The usual disclaimer applies.

${ }^{\dagger}$ Go to https://doi.org/10.1257/aer.p20171078 to visit the article page for additional materials and author disclosure statement(s).
}

of Income and Program Participation (SIPP) that individual real wage growth indeed covaries much more strongly with the aggregate EE transition rate than with the aggregate UE rate.

In this paper, we continue to investigate this hypothesis. Observed wage raises can reflect either reallocation by job movers or rent extraction by job stayers following outside offers. We think of the latter type of wage raises as "inflationary," because they appear like cost shocks. Accordingly, we introduce a statistical framework to measure the covariance structure of nominal, rather than real, wage growth and labor market transitions. We ask whether a counterfactual transition rate (EE, UE, etc.) that applies to each worker covaries with his wage growth, even when no individual transition occurs. This counterfactual is built by projecting actual transitions on a rich set of observable worker and job characteristics and on calendar time. In order to entertain the hypothesis of a Phillips curve, we also include in this covariance structure the unemployment rate. We interpret our results through the lens of the sequential auction (SA) framework introduced by Postel-Vinay and Robin (2002), which allows for renegotiation. Job stayers may obtain wage raises even in steady state when they receive outside offers. Aggregate shocks leave the wage of a job stayer unchanged until an outside offer actually arrives and triggers renegotiation. Then, either the worker still quits to a more productive job, or he receives a matching offer from his current employer and stays.

\section{Data}

We begin with a description of some basic patterns found in the data. As in Moscarini and Postel-Vinay (2016) we draw our data from the SIPP 1996-2008 panels, covering 1996-2013 with few gaps. To refine the measurement of EE transitions, we adopt the methodology and results from Fujita, Moscarini, and Postel-Vinay 
(2017). They use job IDs, start and end dates of jobs as well as weekly labor force status to construct spells of employment, nonemployment, and job switches. The main innovation is the imputation of $\mathrm{EE}$ transitions to individuals whose information goes missing before the end of the panel, either temporarily (gaps) or permanently (attrition). The imputation is based on observed characteristics of the worker, the spell, and the job, as well as aggregate transition rates from the monthly Current Population Survey, to capture trends and business cycles from an equally representative but different dataset.

We study two measures of wages: for all employed workers, nominal monthly earnings, and for hourly paid workers only (about 60 percent of the sample) the reported hourly pay rate. We take log changes in wages as the main variable of interest. The main reason to privilege changes over levels is that in any canonical equilibrium model of a labor market where employed workers search on the job, wages can be sticky in average level due to past commitments, while transition rates respond to job creation and are forward-looking, like wage growth. In addition, an EE transition is typically associated in the data with an unusually large and positive average change in wages, as the worker climbs the job ladder and possibly reallocates to a more productive match. We are mostly interested in separating this direct effect of EE transitions on wage growth from the indirect, unobserved rent-extraction effect due to wage renegotiation following outside offers, which puts pressure on production costs.

In Figure 1 we plot the monthly log change of nominal earnings and hourly wage rate along with the two main transition rates of interest, EE and UE, each averaged across all valid records each month, with person weights, and then linearly detrended. The cyclical comovement between all three variables is visible, but EE appears to comove more strongly. A simple regression confirms the visual impression: both measures of labor income growth covary more strongly with EE than with UE. The rest of this paper is dedicated to an in-depth investigation of these raw aggregate correlations.

\section{Statistical Model}

We present a flexible statistical model designed to extract the covariance over time between wage growth and various stock and flow measures of the state of the labor market. We stress that this covariance structure has no causal interpretation: our goal is to reveal time comovements of wage inflation and labor market outcomes, just as in the original Phillips curve.

From now on we refer to "wage growth" as the month-over-month change in the natural logarithm of either monthly nominal earnings reported by all workers, or of nominal hourly wage rate reported by hourly paid workers. We study the time-covariance structure of wage growth with various labor market transitions. To correct in a very flexible way for sample composition and eliminate cross-sectional covariance, we proceed as follows.

For each individual $i$ at time $t$ let $y_{i t}$ be either: wage growth (denoted $\left.\Delta w_{i t}\right)$, an indicator of unemployment $\left(U_{i t}\right)$, or an indicator of labor market transition: $E E_{i t}, U E_{i t}, E U_{i t}, N E_{i t}$, $E N_{i t}$. We partition the sample into cells defined by a set of $K$ categorical individual characteristics $\left\{z_{i t}^{k}\right\}_{k=1}^{K}$, where each $z^{k}$ takes values in $n_{k}$ classes. In what follows, we refer to a thus defined cell as a "market." Letting $I$ denote the indicator function, we construct $n_{1} \times \cdots \times n_{K}$ "market dummies":

$$
m_{i t}^{j_{1}, j_{2}, \ldots, j_{K}}=\prod_{k=1}^{K} I\left(z_{i t}^{k}=j_{k}\right) .
$$

The dummy $m_{i t}^{j_{1}, j_{2}, \ldots, j_{K}}$ takes a value of 1 if individual $i$ has characteristics $z_{i t}^{k}$ at time $t$ that fall into classes $\left\{j_{1}, j_{2}, \ldots, j_{K}\right\}$, and 0 otherwise. We collate all such dummies into the vector $M_{i t}$. We further interact those market dummies $M$ with calendar time $s=1,2, \ldots, T$ to construct a full set of "market-time dummies":

$$
M_{i t}^{s}=I(s=t) \times M_{i t} .
$$

Then we proceed in two steps. In the first step we filter out observable characteristics from each variable of interest $y$ to eliminate composition effects. To this purpose, for each variable of interest $y$ we run an OLS regression

$$
y_{i t}=X_{i t}^{y} \beta_{y}+M_{i t}^{t} \gamma_{y}+\varepsilon_{i t}
$$

with person weights, where $X_{i t}^{y}$ is a set of individual and job characteristics relating to the job at date $t-1$ (i.e., before the wage growth or transition occurred). Note that we partition observable 
Panel A. Growth in nominal earnings, EE and UE

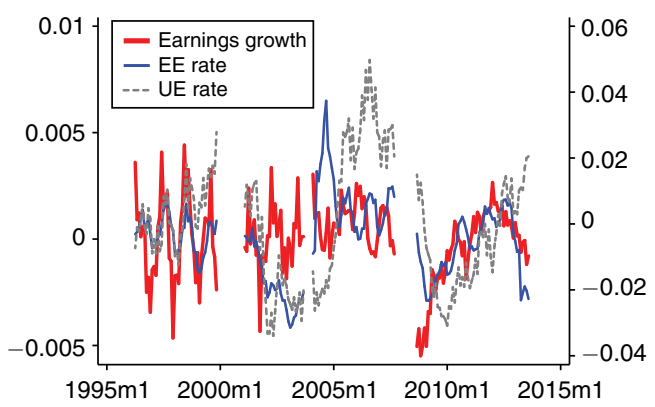

Panel B. Growth in nominal hourly wage rate, EE and UE

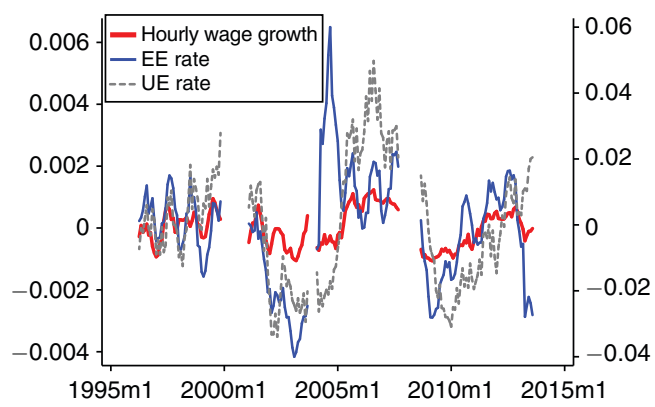

Figure 1. Wage Growth and Transition Rates, Detrended

Notes: All series are smoothed by two-quarter, two-sided MA averaging. Wage growth and EE rate are on the left scale, UE rate on the right scale.

worker and firm characteristics into a set $X^{y}$ that enters this preliminary regression additively, without interactions, and a set $M^{t}$ that enters as fully interacted dummies, including time effects. We conclude the preliminary step by extracting the estimated market-time fixed effects for the variable of interest $y$ :

$$
\hat{\Phi}_{i t}^{y}=M_{i t}^{t} \hat{\gamma}_{y}
$$

Note that, for any given $y$, each of these market-time fixed effects takes the same value for all individuals $i$ who share the same characteristics $z_{i t}^{k}$ at the same time $t$.

In the second main step we run an OLS regression of market-time fixed effects on each other:

$$
\begin{aligned}
\hat{\Phi}_{i t}^{\Delta w}= & \sum_{h \in\{U, E E, U E, E U, E N, N E\}} \hat{\Phi}_{i t}^{h} \delta_{h}+M_{i t} \psi \\
& +\phi t+\eta_{i t}
\end{aligned}
$$

with person weights. This is a regression of the market-time estimated fixed effects for wage growth $\hat{\Phi}^{\Delta w}$ on the analogous market-time fixed effects for unemployment $U$ and transition rates EE, UE, etc., a linear time trend, and a fixed effect of the market itself $M_{i t}$, as defined by the characteristics $z$ but not by calendar time. We think of $\hat{\Phi}^{\Delta w}$ as a measure of latent wage growth that applies to all workers in a given market, and of the other market fixed effects $\hat{\Phi}_{i t}^{h}$ as counterfactual unemployment and transition rates, which estimate how likely worker $i$ would be at time $t$ to find another job either from employment or unemployment, or to be unemployed, based on what is currently happening to workers in the same market $M_{i t}^{t}$. The estimated coefficients $\hat{\delta}_{h}$ thus measure the covariance over time of wage growth with unemployment and labor market transitions within each market, after detrending and after controlling, in the preliminary step, for worker and job characteristics $X$.

\section{Empirical Implementation and Results}

We define a market $M$ as the intersection of age (5 groups), education (5), race (2), gender (2), and calendar time (176 months), a total of $5 \times 5 \times 2 \times 2 \times 176=17,600$ market-time dummy variables. The linear time trend captures both trends in productivity growth and in inflation (both declined in the United States over the 1996-2013 period). The additive controls $X^{y}$ are, for all individuals, state of residence, for employed workers also union status, employer size ( 3 classes), major industry (12) and occupation (5), and a government worker dummy. This is a total of $1+2+11+4+1=19$ additional dummy covariates. We would like to "move" as many observable characteristics from the additive set $X$ to the fully interacted market dummies $M$, but we are constrained by sample size.

In the first step, in the EE transition regression we also control additively for the lagged level of the wage, and in the wage growth regression for the actual occurrence of an $E E_{i t}$ transition for that worker. The estimated effects are consistent with the logic of a job ladder model: workers who are underpaid, given their observable 
Table 1 -Covariance Structure of Earnings/Wage Growth and Labor Market Transitions

\begin{tabular}{|c|c|c|c|c|c|c|c|}
\hline \multicolumn{8}{|c|}{ Dependent variable: log change in monthly nominal earnings } \\
\hline EE rate & $\begin{array}{c}0.0287 \\
(0.0006)\end{array}$ & & & $\begin{array}{c}0.0424 \\
(0.0006)\end{array}$ & $\begin{array}{c}0.0383 \\
(0.0006)\end{array}$ & $\begin{array}{c}0.0423 \\
(0.0006)\end{array}$ & $\begin{array}{c}0.0415 \\
(0.0006)\end{array}$ \\
\hline UE rate & & $\begin{array}{c}-0.0004 \\
(0.00004)\end{array}$ & & $\begin{array}{l}-0.0005 \\
(0.00004)\end{array}$ & $\begin{array}{c}-0.0011 \\
(0.00004)\end{array}$ & $\begin{array}{c}-0.0011 \\
(0.00004)\end{array}$ & $\begin{array}{c}-0.0011 \\
(0.00004)\end{array}$ \\
\hline $\mathrm{U}$ rate & & & $\begin{array}{c}-0.0184 \\
(0.0003)\end{array}$ & & $\begin{array}{c}-0.0170 \\
(0.0004)\end{array}$ & $\begin{array}{r}-0.0096 \\
(0.0003)\end{array}$ & $\begin{array}{r}-0.0096 \\
(0.0003)\end{array}$ \\
\hline EU rate & & & & & & $\begin{array}{r}-0.0500 \\
(0.0007)\end{array}$ & $\begin{array}{r}-0.0500 \\
(0.0007)\end{array}$ \\
\hline NE rate & & & & & & $\begin{array}{c}0.0257 \\
(0.0002)\end{array}$ & $\begin{array}{c}0.0257 \\
(0.0002)\end{array}$ \\
\hline EN rate & & & & & & $\begin{array}{r}-0.0786 \\
(0.0005)\end{array}$ & $\begin{array}{r}-0.0786 \\
(0.0005)\end{array}$ \\
\hline$($ EE rate $) \times$ switcher & & & & & & & $\begin{array}{c}0.0312 \\
(0.0037)\end{array}$ \\
\hline
\end{tabular}

Observations

$10,784,966$

Dependent variable: monthly log change in nominal hourly wage rate

0.0110

(0.0002)

$\begin{array}{cccc}0.0189 & 0.0177 & 0.0169 & 0.0162 \\ (0.0002) & (0.0002) & (0.0002) & (0.0002)\end{array}$

UE rate

$-0.0015$

$(0.00002)$

$\mathrm{U}$ rate

EU rate

$-0.0084$

$(0.0001)$

$\begin{array}{llll}-0.0015 & -0.0019 & -0.0019 & -0.0019\end{array}$

$\begin{array}{llll}(0.00002) & (0.00002) & (0.00002) & (0.00002)\end{array}$

NE rate

EN rate

$($ EE rate $) \times$ switcher 
rate. The estimated coefficient of the job finding rate from unemployment, UE, is consistently negative. The expected, positive sign appears instead for the NE exit rate from nonparticipation to employment. Finally, the exit rates from employment EU and EN have negative and large estimated coefficients.

We perform two robustness checks, which deliver qualitatively similar results. First, on our specification of a "market." We repeat the exercise by controlling in the first step for demographics and time in an additively separable manner. We then run a regression of the estimated time effect of wage growth on estimated time effects of transitions rates and unemployment. Second, on the sample selection for the second step. Individuals who belong in the same market-time are assigned the same, corresponding fixed effects, but contribute different person weights to the regression. The above results refer to all individuals aged 16 to 65 , whether they were employed or not. This in the spirit of interpreting these fixed effects as counterfactuals, as market averages across observationally similar workers, independently of their unobserved characteristics that correlate with employment status. We repeat the second step only on workers who are employed in consecutive months, thus have a valid observation for wage growth.

\section{Discussion}

Overall, we find that the positive covariance over time between wage growth and job-to-job transition rates is supportive of a job ladder model with wage posting, with or without renegotiation. The positive comovement between wage growth of job stayers and EE transitions of observationally similar workers could be due to a common, unobserved factor, such as a shock to labor demand for that type of worker, leading firms to post more vacancies and raising opportunities for EE transitions. This common factor, however, should be captured by actual $E E_{i t}$ transitions, that we introduce in the last specification. Any residual comovement between wage growth of job stayers and the pace of EE reallocation in their labor market should only be due to rent extraction, either through pre-emptive wage raises or through matched and thus declined outside offers, that we do not directly observe. We envision this wage pressure as an important source of cost pressure on firms.

The robustly small, and often negative, covariance between wage growth and UE exit rate from unemployment to employment is difficult to reconcile with the standard search and matching model, where wages are negotiated between workers and firms by Nash bargaining, with unemployment being the worker outside option. Whether wage growth and UE rate respond to a common labor demand shock, or independent movements in UE affect wages through the value of the outside option, the covariance should be positive. We thus find no empirical evidence to support the view that workers, when negotiating their wages, have a credible threat to quit to unemployment, whose continuation value naturally depends on how easy it would be to then find alternative employment. Our evidence is instead consistent with a credible threat to quit, hence an ability to extract a wage raise, only once an alternative offer has arrived, or is likely to arrive soon. While both UE and EE transitions strongly comove over time in response to common labor demand shocks, only the latter captures the expected pressure on wage growth.

\section{REFERENCES}

Burdett, Kenneth, and Dale T. Mortensen. 1998. "Wage Differentials, Employer Size, and Unemployment." International Economic Review 39 (2): 257-73.

Fujita, Shigeru, Giuseppe Moscarini, and Fabien Postel-Vinay. 2017. "Employer-to-Employer Reallocation." Unpublished.

-Mortensen, Dale T., and Christopher A. Pissarides. 1994. "Job Creation and Job Destruction in the Theory of Unemployment." Review of Economic Studies 61 (3): 397-415.

-Moscarini, Giuseppe, and Fabien Postel-Vinay. 2013. "Stochastic Search Equilibrium." Review of Economic Studies 80 (4): 1545-81.

Moscarini, Giuseppe, and Fabien Postel-Vinay. 2016. "Wage Posting and Business Cycles." American Economic Review 106 (5): 208-13.

- Postel-Vinay, Fabien, and Jean-Marc Robin. 2002. "Equilibrium Wage Dispersion with Worker and Employer Heterogeneity." Econometrica 70 (6): 2295-2350. 